\title{
Multimodal Document Management in Radiotherapy, an Update
}

\author{
Harald Fahrner ${ }^{1 *}$, Stefan Kirrmann ${ }^{2 *}$, Mark Gainey ${ }^{1}$, Marianne Schmucker ${ }^{1}$, Martin Vogel ${ }^{2}$, \\ Felix Heinemann ${ }^{1}$ \\ 1 Klinik für Strahlenheilkunde, Department für Radiologische Diagnostik und Therapie, Universitätsklinikum Freiburg \\ 2 Steinbeis Forschungszentrum für Medizintechnik und Biotechnologie, Weinheim \\ * are equally contributing authors \\ Correspondence: Dr. med. Felix Heinemann, Klinik für Strahlenheilkunde, Department für Radiologische Diagnostik und Therapie, \\ Universitätsklinikum Freiburg, Robert Koch Str. 3, 79106 Freiburg, \\ Tel. +49 761 270-94550, Fax +49 761 270-95520 \\ E-Mail: felix.heinemann@uniklinik-freiburg.de
}

\begin{abstract}
Background: In 2013, we presented a study entitled "Multimodal document management in radiotherapy", demonstrating the excellent routine performance of the system about four years after its initiation by evaluating a sample of $n=500$ documents. During this time the system saw additional developments and significant improvements: the most important innovative step being the automatic document processing. This has been completely reworked, to minimize staff-machine interaction, to increase processing speed and to further simplify the overall document handling. This improved system has been running practically without any problems for several months. Methods: While reworking the automatic document processing, we have developed algorithms that allow us to transfer documents with varying type, within a single scanning procedure, into our departmental system. The system identifies and corrects for any arbitrary order or rotation of scanned pages. Finally, after the transfer into the departmental system, all documents are in the correct order and they are automatically linked to the respective patient record. Results: According to our surveys, the error rate of the system, as in the previous version, is $0 \%$. Compared to manual scanning and mapping of documents, we can quantify a 30-fold increase in the processing speed. In spite of these additional and elaborate processes, code optimizations yielded a processing speed increase of $20 \%$. Pre-sorting of the documents (e.g., medical reports, or documents of informed consents) can be completely dispensed with the automated correction for jumbled documents or document rotations. In this manner 25,000 documents are automatically processed each year in the Department of Radiation Oncology at the University of Freiburg. Conclusion: With the methods presented in this study, and some additional bug fixes, and small improvements, automatic document processing of our departmental system was significantly improved without compromising the error rate.
\end{abstract}

Keywords: Clinic management, documents, workflow, optimisation, efficiency, automation, Mosaiq, oncology informatics

\section{Introduction}

Since 2013, all data-related processes and procedures in our Department (of Radiation Oncology), have been digitized [1]. In addition to the integration of the therapy schedules, the consulting schedules and the organizational mapping of the treatment planning into our departmental system $[2,3]$, all document types were included in the digital setting [4]. The scope of the present study was to minimize staff-machine interaction, to increase processing speed and to further simplify the overall document handling. In parallel, all previously established standards with respect to security, process control and logging were reviewed and have been improved if necessary.

Material and Methods

The implementation of an electronic patient record
(EPR, for abbreviations see legend, table 2 ) is a prerequisite to operate an efficient digital document management [5]. Yet, this prerequisite is not sufficient, as there are many types of documents that are not created directly in an electronic file. Therefore they have to be included in the EPR in the appropriate quality so that the system-users have fast and secure access to all data linked to a specific patient. In 2009, as part of our digitalization, we first integrated all therapy schedules, consulting schedules and the organizational mapping of the radiotherapy treatment schedules $[2$, $3]$ into our departmental system, including DICOM [6, 7] and DICOM-RT [8, 9] based imaging data [10], in order to ensure an efficient treatment process. An additional prerequisite is a safeguard concept for backup and archiving [1113].

Usability and effectivity of the system is further in-

This article is licensed under the Creative Commons Attribution 4.0 International License. To view a copy of this license, visit http://creativecommons.org/licenses/by/4.0/ or send a letter to Creative Commons, PO Box 1866, Mountain View, CA 94042, USA. Creative Commons Attribution 4.0 International license. (cc) EY 


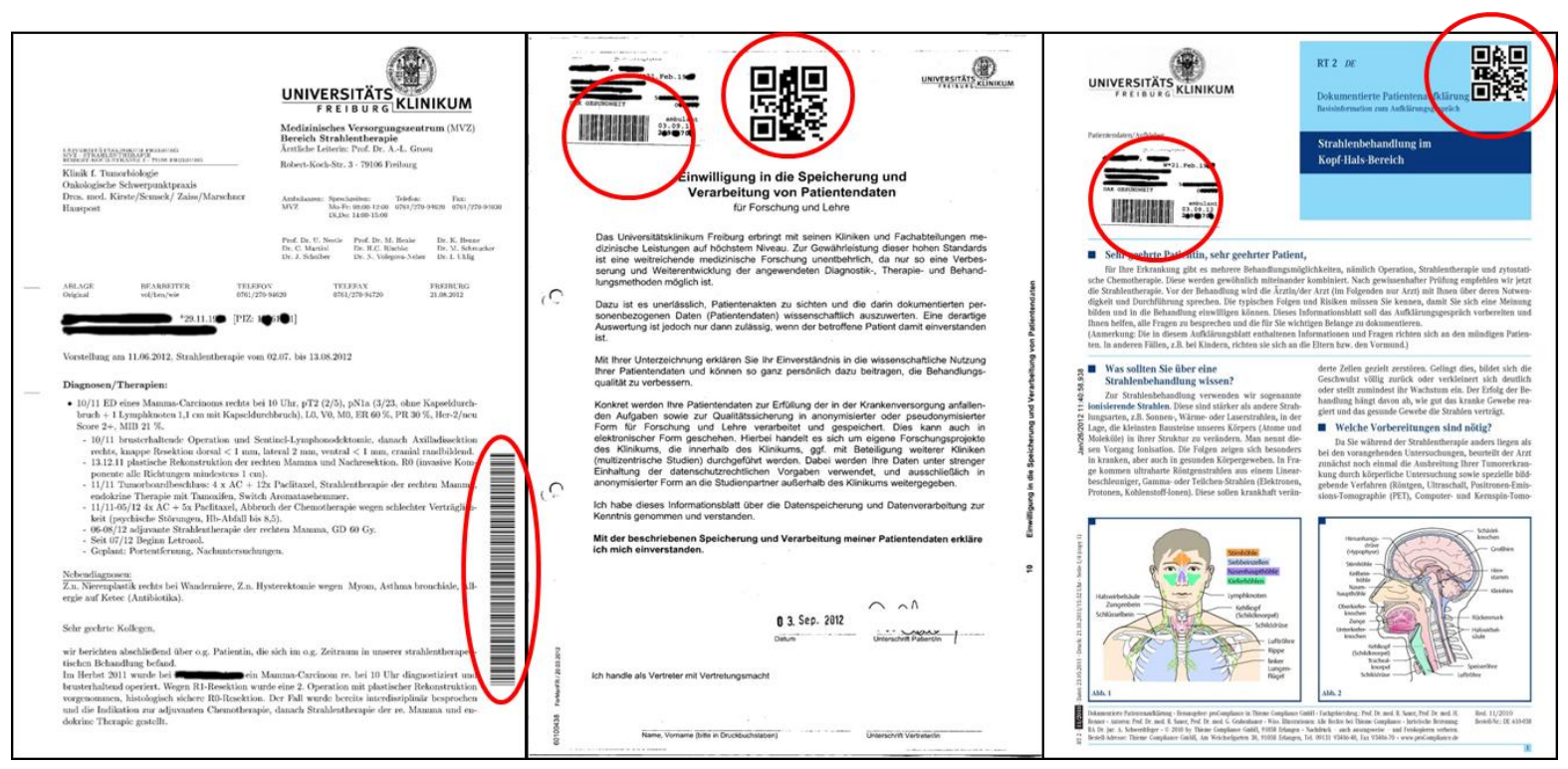

Figure 1. Design of documents for the automated import; Barcodes are highlighted in red elipses.

creased if interfaces to other clinical IT systems such as the hospital information system (HIS), for example, can be established. Today, error-free design and use of interfaces is still a technical challenge. Thus, in parallel to the project presented here, we have re-compiled all our interfaces implemented to date into a single platform. This multifunctional interfacing tool provides for approximately 70 communication channels, which, for the most part, are implemented with the open source tool mirth [14].

The presented developements builds on a previous publication from 2013 [4] and it details the automation of internal, paper-based, barcoded (see figure 1) documents (referred to as "type B documents" in reference 4] [15]. Table 1 depicts all types of documents in question.

As previously described, all documents are imported into the departmental information system MOSAIQ directly where they are created by the responsible personnel. This yields immediate and high availability of the digitized data and information in the departmental system. Due to the large amount of documents, tagging of all imports with qualified labels is essential (see table 1). Since each document is provided with a barcode or QR code, the automated recognition and thus the clear and qualified assignment are possible with a low error rate (see figure 1).

The system consists of 4 Windows 32-Bit modules (inhouse developments).

1. Int-Doc (physicians's letter system)

- generates documents with unique barcodes (Code 39)

- $\quad$ programming environment: Harbour, Borland $\mathrm{C}++, \mathrm{MS}-\mathrm{SQL}$

2. Form-Pool (form pool)

- $\quad$ provides all necessary official forms

- $\quad$ forms are prepared to include unique barcodes (Code 39) and identifiers

- $\quad$ programming environment: Adobe Acrobat FDF feature

3. Document-Printer (form printing)

- $\quad$ user selects a form

- $\quad$ program assigns id and bar codes to the selected form (using the command line tool PDFTk)

- $\quad$ program prints this form

- $\quad$ programming environment: AutoIt, PDFTk,

Table 1

Document types with qualifiers

\begin{tabular}{|l|l|l|l|}
$\begin{array}{l}\text { Qualified identifier in } \\
\text { MOSAIQ }\end{array}$ & Source & $\begin{array}{l}\text { Import } \\
\text { by }\end{array}$ & Document description \\
\hline Arztbrief intern & intern & SEC & internal doctor's letter (letters created by us) \\
\hline Einverst. FL & intern & PM & consent form research and education \\
\hline Einverst. KMiv & intern & PM & consent form i.v. contrast medium \\
\hline Einverst. RT & intern & PM & consent form radiotherapy \\
\hline Einverst. Chem & intern & PM & consent form chemotherapy \\
\hline
\end{tabular}


C.Net, MySQL

4. Data-Director (import and distribute documents)

- scans a batch of documents

- reads barcodes (Codabar, Code 39) (using command line tool TWAINCommander)

- automated correction for jumbled documents or document rotations ( $\mathrm{x}$ or $\mathrm{y}$ )

Table 2

Legend

\begin{tabular}{|c|c|c|c|}
\hline AutoIt & $\begin{array}{l}\text { Freeware BASIC-like Scripting Lan- } \\
\text { guage } \\
\text { AutoIt Consulting Ltd, Wales, England }\end{array}$ & Javascript & $\begin{array}{l}\text { Web scripting language from } \\
\text { Netscape }\end{array}$ \\
\hline C.Net & $\begin{array}{l}\text { C language in .Net Framework from } \\
\text { Microsoft }\end{array}$ & HIS & Hospital Information System \\
\hline $\mathrm{C}++$ & $\begin{array}{l}\mathrm{C} \text { programming language IDE from Bor- } \\
\text { land }\end{array}$ & KV & Health Insurance Association \\
\hline Codabar & $\begin{array}{l}\text { linear barcode, } 12 \text { symbols (digits } 0-9 \text {, } \\
\text { dash, and } \$ \text { ), additional } 4 \text { symbols }(: /+.) \\
\text { and } 4 \text { start and stop symbols (designated } \\
\text { ABCD) }\end{array}$ & MEDATEC & $\begin{array}{l}\text { Medical Data and Text pro- } \\
\text { cessing with Computer (in- } \\
\text { house development) }\end{array}$ \\
\hline Code 39 & $\begin{array}{l}\text { linear barcode, } 43 \text { characters, uppercase } \\
\text { letters }(\mathrm{A}-\mathrm{Z}) \text {, digits }(0-9) \text {, special charac- } \\
\text { ters }(-, ., \$, /,+, \% \text {, ‘). Character }(*) \text { is } \\
\text { the delimiter for start and stop. }\end{array}$ & MIRTH & $\begin{array}{l}\text { Interface System } \\
\text { Product of QSI Management }\end{array}$ \\
\hline $\mathrm{CT}$ & Computer Tomography & MOSAIQ & $\begin{array}{l}\text { Departemental System } \\
\text { Product of ELEKTA }\end{array}$ \\
\hline DICOM & $\begin{array}{l}\text { Digital Imaging and Communications in } \\
\text { Medicine }\end{array}$ & MS-SQL & $\begin{array}{l}\text { Data-management System (Mi- } \\
\text { crosoft) }\end{array}$ \\
\hline $\begin{array}{l}\text { DICOM- } \\
\text { RT }\end{array}$ & Extension of DICOM for treatment data & MySQL & $\begin{array}{l}\text { Data-management System (Or- } \\
\text { acle) }\end{array}$ \\
\hline DIN & German Institute for Standardization & PDF & $\begin{array}{l}\text { Portable Document Format } \\
\text { (Adobe Inc.) }\end{array}$ \\
\hline DB & Database & PDFTk & $\begin{array}{l}\text { PDF-command line tool to fill } \\
\text { in PDFs from FDF source }\end{array}$ \\
\hline EPR & Electronc Patient Record & PID & Patient Identifier \\
\hline FDF & Acrobat Forms Data Format (Adobe) & PM & Patient Management \\
\hline $\begin{array}{l}\text { FINDING } \\
\text { SERVER }\end{array}$ & $\begin{array}{l}\text { A central platform of the hospital, which } \\
\text { receives (via HL7), manages and pro- } \\
\text { vides documents and findings from all } \\
\text { departments. }\end{array}$ & QM & Quality Management \\
\hline Harbour & xbase compiler open source & SEC & Secretary \\
\hline HL7 & $\begin{array}{l}\text { Health Level Seven (standard for ex- } \\
\text { changing information between medical } \\
\text { applications) }\end{array}$ & SQL & Structured Query Language \\
\hline ID & Identifier & TWAINCommander & $\begin{array}{l}\text { Scanning command line Tool } \\
\text { JSE Imaging Solutions Lim- } \\
\text { ited, Langenfeld, Germany }\end{array}$ \\
\hline IMRT & Intensity Modulated Radiation Therapy & Windows & Operating system (Microsoft) \\
\hline
\end{tabular}

Figure 2 depicts the previous automatic import workflow, which, in the last three years, has been found to be effective. It can be seen that with this version, it was already possible to process multiple documents in one scanning step. This was limited, however, by the condition that the individual documents had to be inserted in the correct order and alignment. Incorrect links were corrected by error
- interface to distribute data to subsystems (MOSAIQ and HIS) (improved interface based on 'mirth')

- programming environment: AutoIt, C.Net, MySQL database, TWAINCommander management implemented in software with error rates of $0 \%$. In contrast manual imports resulted in error rates of up to 2 per cent (evaluation of multiple samples of documents, $\mathrm{n}=200$ each). Detailed $\log$ files were created so that each scan is documented and trackable. The improved workflow presented in this study is shown in figure 3 . 


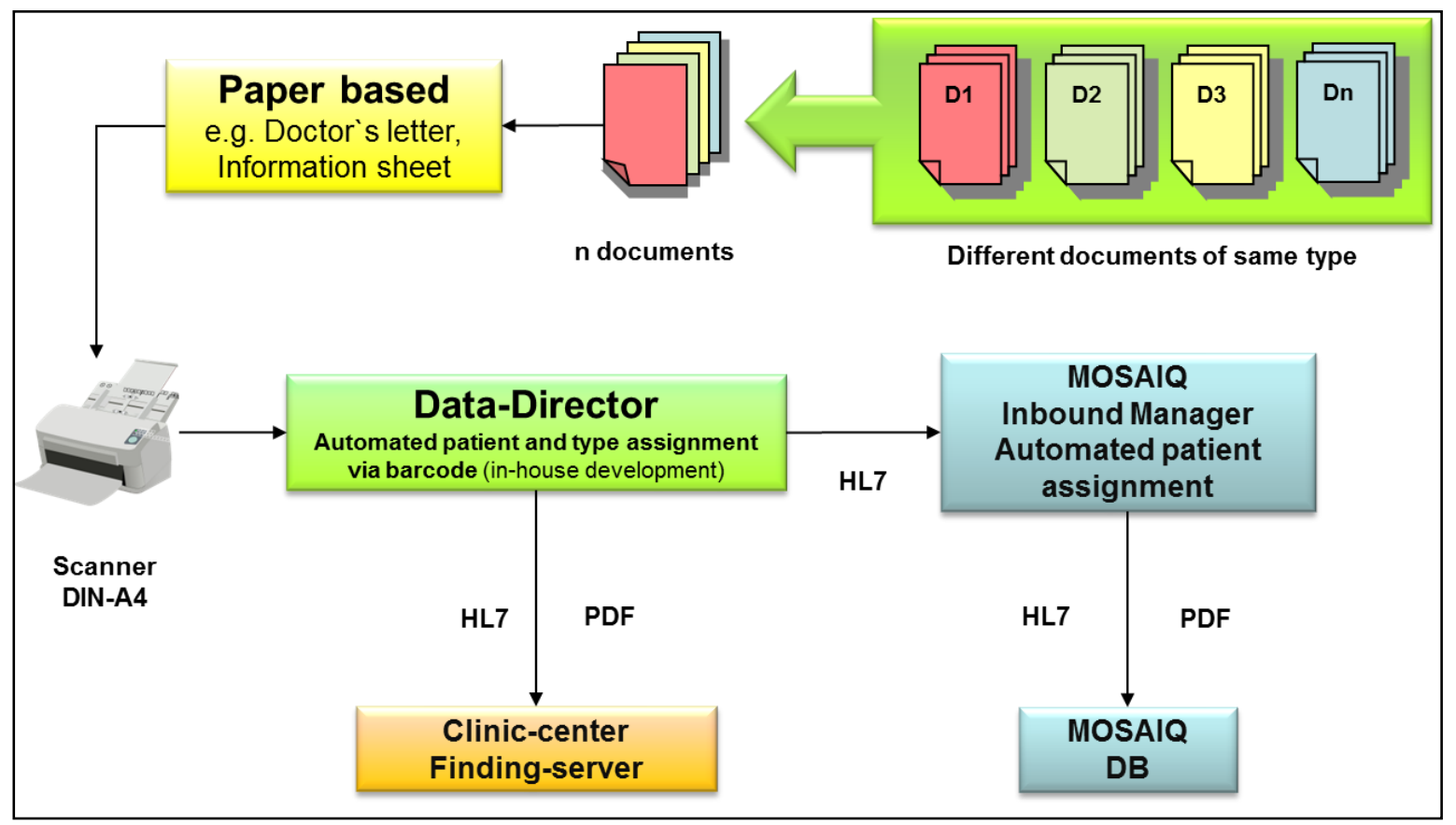

Figure 2. Previous digital workflow of documents.

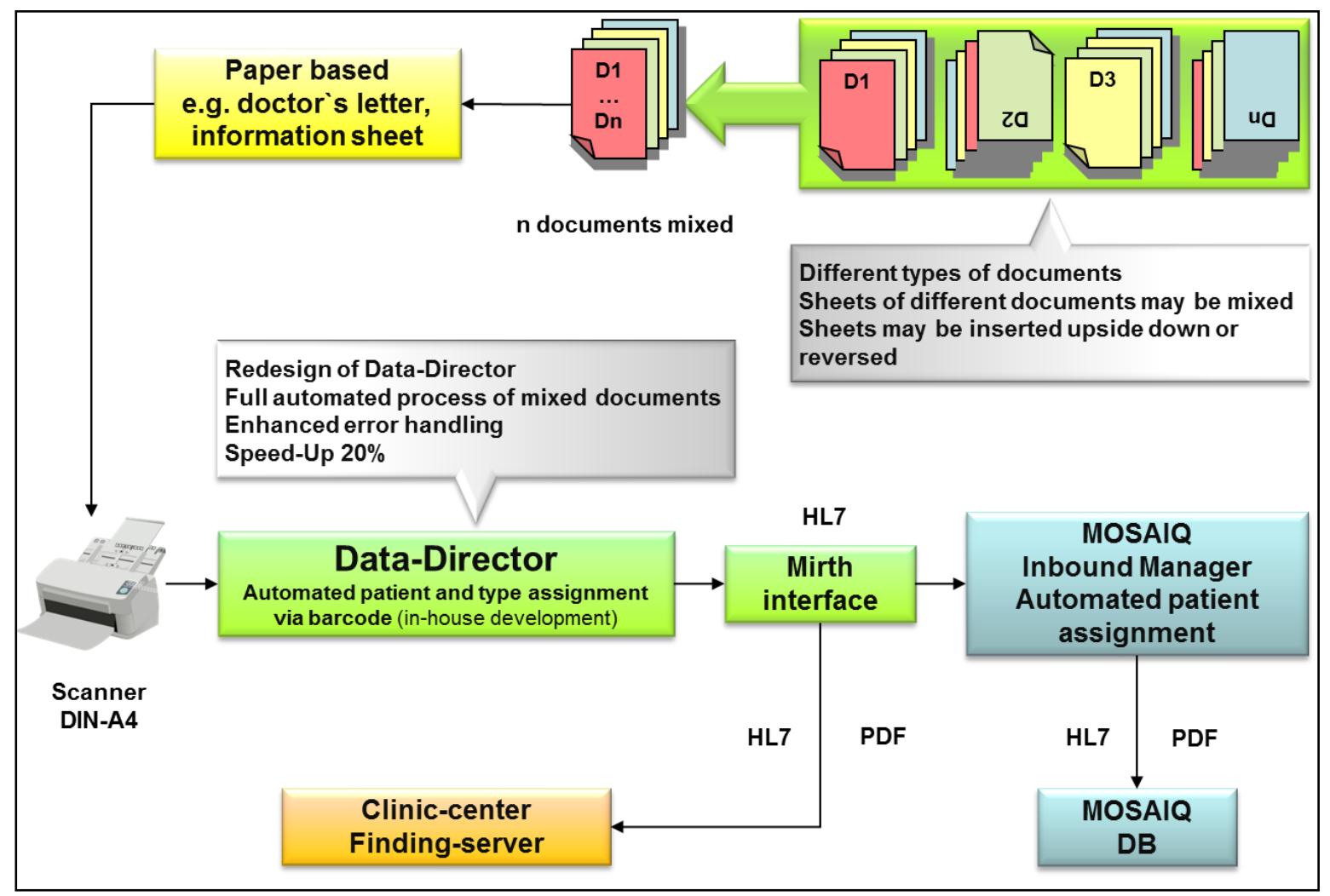

Figure 3. Improved digital workflow of documents. 
In addition to improvements applied to preexisting software logic and error management, the 'Data-Director' has been completely redesigned, where the existing algorithms have been optimized especially with regard to speed. In parallel and within an additional project, all interfacing functionalities have been consolidated to an unified platform ('mirth'), including the new interfaces from the present study which consist mainly of HL7- and SQL-queries for direct database access [16-18], thus eliminating all previous proprietary interface modules. The redesign included a complete rework of the user interfaces, streamlining the configuration and administration of the system and the development of algorithms that enable the processing of various document types with arbitrary mixing of pages in a single scanning step. A detailed description of all these measures is beyond the scope of this study. This approach no longer necessitates collecting and binding documents by type, order and/or orientation. In spite of the additional computing power needed for this feature, processing speed was increased by approximately $20 \%$; we evaluated the processing time of the improved system with $n=50$ samples (same samples were used for both systems). In our analysis of 200 samples, the error rate (i.e., documents linked to the wrong patient record) was $0 \%$. This is probably because we use the same barcode type (Codabar) and the same algorithm for checksum calculations of the Patient Identifier (PID) as our Computer Centre of the hospital (table 3). In a time comparison ( $\mathrm{n}=20$ samples) between automatic and manual scanning and mapping of documents, we were able to quantify a 30 -fold increase in processing speed.

Table 3

Patient identifier (PID) validity check.

\begin{tabular}{ll}
\hline Identifier & Description \\
\hline $\begin{array}{l}\text { Patient Identifier (PID) } \\
\text { check digit (ChkD) }\end{array}$ & has eight digits (12345678) \\
Calculation of Remainder (REM): & is the 8th digit of the PID \\
Sum of REM & \\
$-\quad 2 *$ digit 1 & REM $=2 *$ Value of digit 1 \\
$-\quad(9-n) *$ digit [n] for $n=2 . .7$ & REM $+7 *$ value of digit 2 \\
& REM $+6 *$ Value of digit 3 \\
& REM $+5 *$ value of digit 4 \\
& REM $+=4 *$ Value of digit 5 \\
& REM $+3 *$ Value of digit 6 \\
& REM $+2 *$ value of digit 7 \\
& \\
Modulo & REM $=$ REM modulo 11 \\
& REM $=1$ and ChkD $=0$ \\
PID is valid if: & or \\
& REM $=0$ and ChkD $=0$ \\
& or \\
& $11-\mathrm{REM}=\mathrm{ChkD}$ \\
\hline
\end{tabular}

Figure 4 shows the two basic internal sources of documents. The first source is our form platform, through which all documents based on official forms are offered to the user. For each form, the system assigns barcodes to all associated pages, thereby creating a unique document set. The second source is our physicians's letter system. Each document from this latter system also automatically receives a unique barcode on all associated pages. Since our physicians's letter system is very efficient, the use of the traditional departmental system for writing physicians's letters, which seems rather rudimentary in comparison, is currently out of the question. In addition, the physicians do not want to change the usual workflow with regard to physicians's letters.

We have used the improved work flow clinically for the last 12 months with very high stability (no system crashes or malfunctions; some barcodes were not readable due to crumpled paper, or incomplete printing or the placement of holes for binding). The qualified distribution of digitized documents into subsystems has been streamlined as well; this improvement is largely due to the integration of 'mirth'.

The difference between both work flows is listed in table 4 .

Details about the processing of documents can be found in [1].

Although we have now solved the problem of unambiguous identification of each scanned page, we would like to elaborate one aspect more clearly:

Along with the ongoing digitization of documents, nonDIN forms will be transferred step by step to the standard DIN A4 format. This is desirable and is necessary 
Table 4

Comparison of the two workflow procedures

\begin{tabular}{|l|l|l|}
\hline Mode & Old & New \\
\hline Multiple documents & $\mathrm{x}$ & $\mathrm{x}$ \\
\hline Software interface to HIS and MOSAIQ & $\mathrm{x}$ & $\mathrm{x}$ \\
\hline accurate error messages & $\mathrm{x}$ & $\mathrm{x}$ \\
\hline Different types of documents in one scan & - & $\mathrm{X}$ \\
\hline Mixed Sheets of different documents & - & $\mathrm{x}$ \\
\hline Inserting Sheets upside down & - & $\mathrm{X}$ \\
\hline Inserting Sheets reversed & - & $\mathrm{X}$ \\
\hline Unified software interface & - & $\mathrm{X}$ \\
\hline Simplified Administration & - & $\mathrm{X}$ \\
\hline Simplified Configuration & - & $\mathrm{x}$ \\
\hline Increased Processing speed & - & $\mathrm{x}$ \\
\hline Simplified handling & - & $\mathrm{x}$ \\
\hline
\end{tabular}

for progress (e.g., specific forms from the health insurances). On the other hand, however, folded or multi page forms (e.g., letters of consent) will be transformed into multiple single-page documents which do not have unique identifiers to ensure that they belong to a particular form; as is the case in our centre (figure 5). The connection between those single pages and the corresponding document is therefore lost. Commercial multi-page forms or templates are usually delivered in PDF where not all individual pages have a clear and qualified connection to the document.

In addition, supplementary pages have no empty space where identification labels could be manually attached. We have therefore ensured that all form sets (first and supplementary pages) used in our system (currently 25 forms) can be identified unambiguously at all times. This condition is ensured by a form pool developed in-house where each used or printed form set is unique with all pages included in each set. This means we tag each form type that is officially allowed for use in the whole clinic system, with a unique ID and barcode before it is included in our form pool. Automatic import of forms that are not included in our pool is prohibited by our software systems; users can only import establised forms. In this manner, a mix-up of pages from different form sources is avoided (e.g. page one from letter of consent A, continuation pages from letter of consent B). The establishment of such a departmental form pool brings with it a large overhead of work at the beginning; we needed about a week to complete this in the past. Recently we have changed and simplified this procedure; thus, the insertion of a new form now only takes about 15 minutes. The main task was and is to provide the forms with unique IDs and barcodes (figure 6).

The maintenance has simplified as only few forms have changed since the beginning of clinical operation. The addition of new forms was not necessary to date.

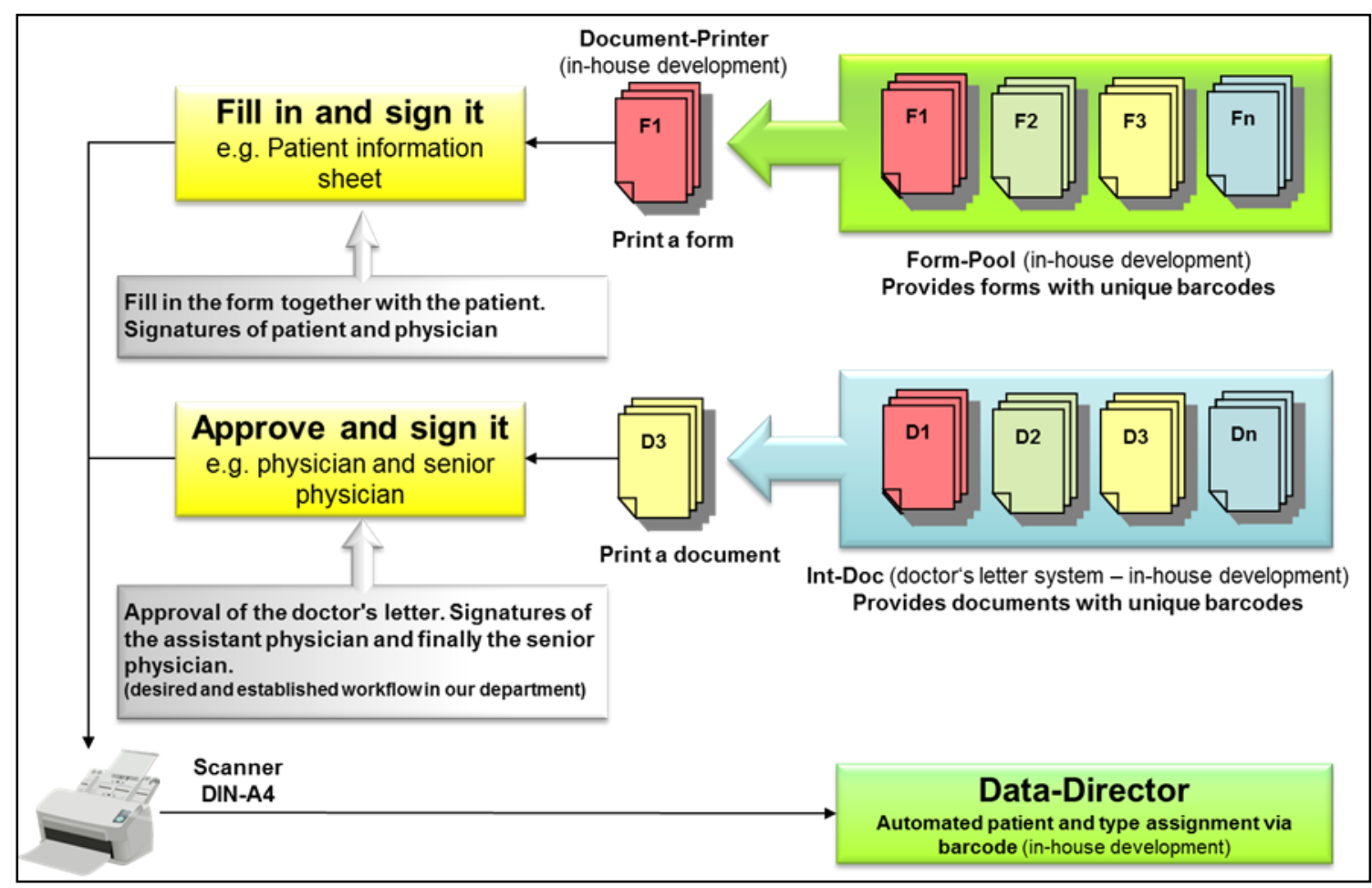

Figure 4. Generating internal documents with barcodes 


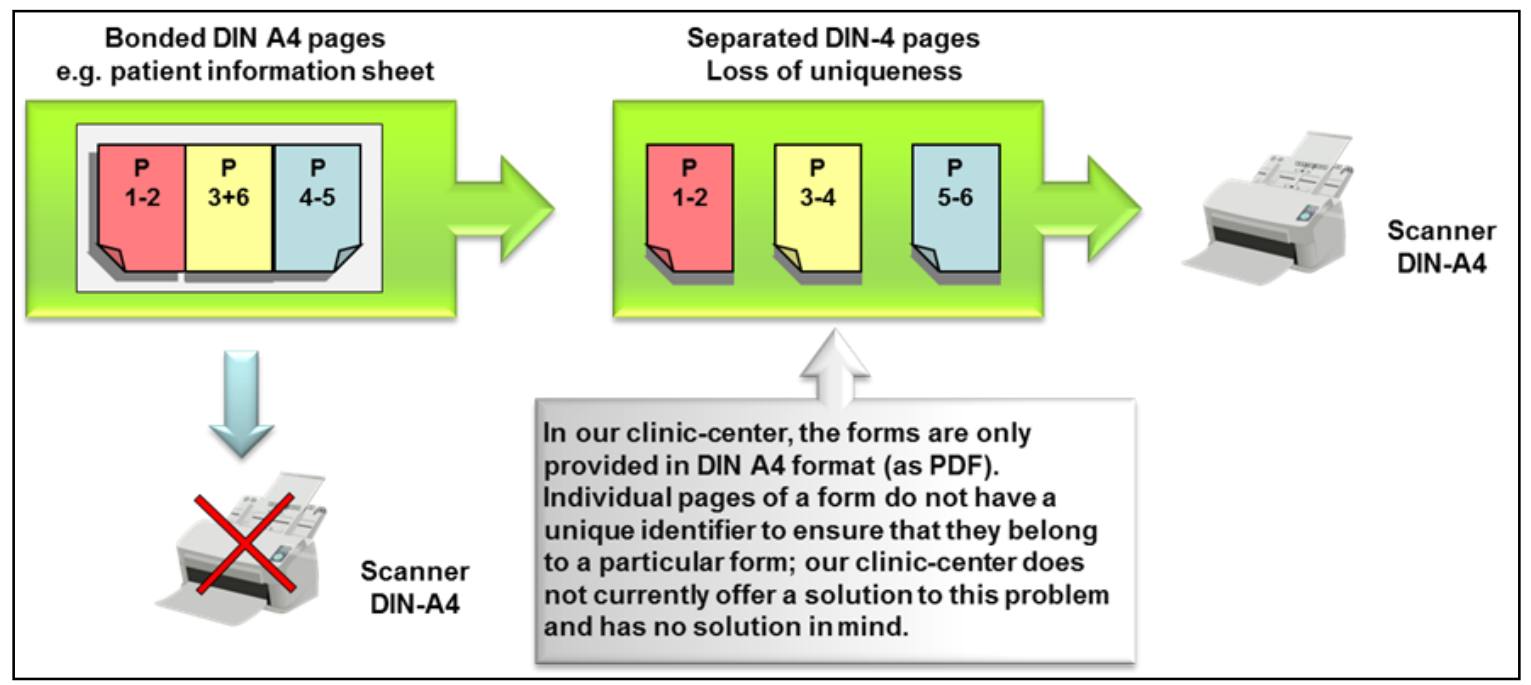

Figure 5. The change of DIN A3 to DIN A4

Yet, the establishment of a system that is entirely automated, and reliable, depends on such a pool as long as there is no interdepartmental solution providing a standard set of documents throughout the organization.

All relevant processes and SOPs (Standard Operating Procedure) have been documented according to the QMS (Quality Management System) of our clinic, the availability of all data for the next 30 years [19], as required by radiation protection regulation [5, 10, 20-22], is ensured.

No additional hardware costs arose with this project as all necessary equipment, as, e.g., high speed scanners, were already in place. Planning and implementation required about 700 working hours within our department. An additional 1300 hours were needed for the other projects such as the interfaces in 'mirth' or the form pool. Outsourcing to a commercial contractor was therefore not economically viable.

The conceptual phase started in January 2014 and lasted until May 2014, followed by the implementation phase from July to August 2016. Routine clinical use of the system started in November 2016.

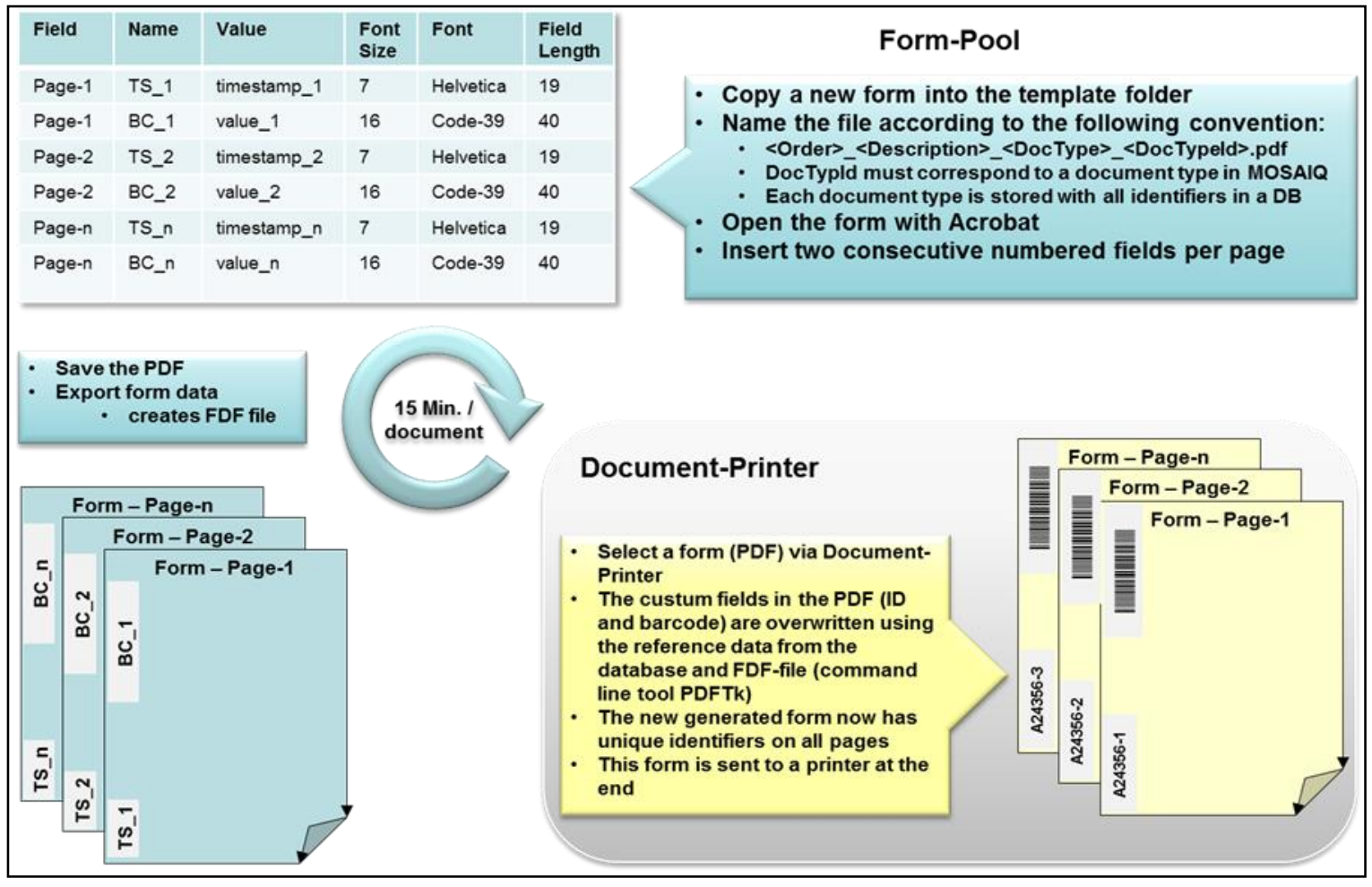

Figure 6. Generating a new form with barcodes and using the Document-Printer 


\section{Results}

After 6 months of clinical use, the new and improved workflow presented here meets all expectations and runs virtually error-free. Increasing the level of automation to $100 \%$ has clear advantages: as we see from samples and analyses of the log files, the new system outperforms manual digitization of documents by a factor of 30 in speed and to date works with an error rate of $0 \%$.

Pre-scan processes have been simplified. Pre-sorting of documents is no longer necessary. Documents can have arbitrary order provided that all pages of one document are present in the paper stack; distributing pages to different stacks will cause an error. However, we plan to extend the software in such a way that the user is automatically asked to add missing pages to the scanner if necessary.

The rate of linking pages to the incorrect patient record is $0 \%$. Usually erroneous allocations could only be caused by either misreading the barcoded ID as a correct ID of a different patient (this has not yet occurred) or by users ignoring warnings from the software (e.g., about missing pages). In the new version of the software, missing pages are treated as an error rather than a warning and dismissing software alerts, about missing pages, is no longer possible. Additional sources of errors, like scanning pages twice, missing pages or distribution of documents to different scan stacks, only occur very rarely. The new work flow conforms to our quality management and is an integral part of the departmental work flow where, approximately 25,000 documents are automatically processed, each year.

We can easily attribute a clear benefit to both the old and new workflows, including the significant reduction of cost and resources.

\section{Discussion}

For three and half years, our department has been working completely paper- and film-less (with the exception of standard mail with extradepartmental partners). The transition from paper and film to a completely digital work environment was not trivial as all processes still have to meet the requirements laid out by the radiation protection regulations. As the digitization of paper documents is very work intensive, with the total amount of documents ever increas- ing, we sought it timely for the means to simplify and, more importantly, to automate all processes. This led to a first project completed in 2013.

Since we work in the context of a large hospital, we often find sub-optimal conditions; such as e.g. a central forms platform that does not yet provide unique form sets and will not implement them in the near future. For automated document processing, however, this is absolutely necessary in order to guarantee proper association of documents (see Methods).

We needed about one week to transfer all the necessary forms to our platform.

However, as these rarely change or potentially only few are added, the effort was and still is kept to a minimum.

Furthermore, in addition to the self-developed software, an interface is required, through which all documents are introduced into the departmental system. Since we have transferred all our interfaces into a common communication platform ('mirth') in another project within the last 3 years, this step was relatively easy to accomplish.

The advanced system has once again led to decisive improvements in terms of handling, reliability and speed. The dependency on a special form platform, another interface and self-developed software complicate the implementation in other institutions.

There is currently one unresolved problem remaining: scanning external documents remains labour intensive. Although we provide optimized and powerful software tools for these tasks too, users still have to manually scan and import the documents into our departmental system, including qualifying and linking them to individual patients.

We are currently not aware of a different system allowing for the same functionality. Moreover in Germany only $25 \%$ of radiation oncology departments work in a purely digital environment [23].

\section{Acknowledgements}

We would like to thank Prof. Anca-Ligia Grosu, Prof. Dimos Baltas, Dr. Eleni Gikka, Mr. Jens Tietjen, Mr. Sebastian Gläß and Mr. Thomas Bach for the constructive discussion on this project.

\section{References}

1. Heinemann F, Röhner F, Schmucker M, Bruggmoser G, Henne K, Grosu A-L, et al. Abteilungs- und Patientenmanagement in der Strahlenheilkunde. Strahlenther Onkol. 2009;185(3):143-54.

2. Röhner F, Schmucker M, Henne K, Momm F, Bruggmoser G, Grosu AL, et al. Integration der Bestrahlungsplanung in den volldigitalen Workflow. Strahlentherapie und Onkologie. 2013;189(2):111-6. doi: 10.1007/s00066-012-0259-0.

3. Torresin A, Carbonini C, Ferrari M, Asnaghi D, Botturi M. Planning and verification in radiotherapy: our experience in a filmless hospital. Polish Journal of Medical Physics And Engineering. 2009;15(2):103-12. doi: 10.2478/v10013-009-0010-z.

4. Fahrner H, Kirrmann S, Rohner F, Schmucker M, Hall M, Heinemann F. [Multimodal document management in radiotherapy]. Strahlenther Onkol. 2013;189(12):1032-9. doi: 10.1007/s00066013-0451-x. PubMed PMID: 24196281.

5. DEGRO. Positionspapier Elektronische Krankenakte in der Strahlentherapie2010.
6. Yu WX, Zhang H, Luo LM. [DICOM in radiotherapy]. Zhongguo yi liao qi xie za zhi $=$ Chinese journal of medical instrumentation. 2002;26(5):352-5. PubMed PMID: 16104266.

7. 7Neumann M. DICOM--current status and future developments for radiotherapy. Zeitschrift fur medizinische Physik. 2002;12(3):171-6. PubMed PMID: 12375450. 8. Law MYY, Liu B. Informatics in Radiology DICOM-RT and Its Utilization in Radiation Therapy. Radiographics. 2009;29(3):655-67. doi: 

WOS:000266790800002.

9. Law MYY, Liu B, Chan LW. DICOMRT-based Electronic Patient Record Information System for Radiation Therapy Radiographics. 2009;29(4):961-U3. doi: 10.1148/rg.294085073. PubMed PMID: WOS:000268325800002.

10. Steil V, Schneider F, Küpper B, Weisser G, Wenz F, Lohr F. Patientenbezogenes Bild- und Datenmanagement in der Radioonkologie. Strahlenther Onkol. 2009;185(1):1-7.

11. Texas Dental Association Financial Services L. Data archiving and backup: what you need to know. Texas dental journal 2007;124(6):612-3. PubMed PMID: 17711053.

12. Behlen FM, Sayre RE, Weldy JB, Michael JS. "Permanent" records: experience with data migration in radiology information system and picture archiving and communication system replacement. J Digit Imaging. 2000;13(2 Suppl 1):171-4. PubMed PMID: 10847391; PubMed Central PMCID: PMC3453274.

13. Avrin DE, Andriole KP, Yin L, Gould R, Arenson RL. Simulation of disaster recovery of a picture archiving and communications system using off-site hierarchal storage management. J Digit Imaging. 2000;13(2 Suppl 1):168-70
PubMed PMID: 10847390; PubMed Central PMCID: PMC3453250.

14. Camacho Rodriguez JC, Staubert S, Lobe M. Automated Import of Clinical Data from HL7 Messages into OpenClinica and tranSMART Using Mirth Connect. Stud Health Technol Inform. 2016;228:317-21. PubMed PMID: 27577395.

15. Dunn R. A quick scan of bar coding. When planning document imaging systems, don't forget the bar codes. J AHIMA. 2006;77(1):50-2, 4. PubMed PMID: 16475736.

16. Flaig M, Graeber S, Sybrecht GW, Innere MV. Use of HL7 to integrate a HISsubsystem: limits and possibilities 2973. MEDINFO 2001. 2001; Proceedings of the 10th World Congress on Medical Informatics. IOS Press. Part vol.1, 2001, pp. 730-4. Amsterdam, Netherlands. PubMed PMID: 2977.

17. Kolovou L, Darras A, Lymbperopulos D, Patras Univ G. HL7 message handling for intra-hospital information systems 2972. CIMED2005.Proceedings of the 2nd International Conference on Computational Intelligence in Medicine and Healthcare. IEE. 2005, pp. 446-53. London, UK. PubMed PMID: 2976.

18. Koncar M. HL7 standard--features, principles, and methodology 9. Acta
MedCroatica. 2005;59(3):273-6. PubMed PMID: 2979.

19. Lohr F, Baus W, Vorwerk H, Schlömp B, André L, Georg D, et al. Rechtliche Grundlagen für den Umgang mit sicherheitsrelevanten Ereignissen in der Strahlentherapie. Strahlentherapie und Onkologie. 2012;188(7):545-50. doi: 10.1007/s00066-012-0119-y.

20. Bundesministerium für Umwelt NuR Richtlinie zur Verordnung über den Schutz vor Schäden durch ionisierende Strahlen (Strahlenschutzverordnung - StrlSchV)2017.

21. Swerdloff SJ. Data Handling in Radiation Therapy in the Age of ImageGuided Radiation Therapy. Seminars in Radiation Oncology. 2007;17(4):287-92. doi: 10.1016/j.semradonc.2007.08.002.

22. Sietmann R. Gerichtsfest archivieren. $\mathrm{C}^{\prime} \mathrm{T}$ Magazin für Computertechnik. 2008;2:46-7.

23. Kirrmann S, Fahrner H, Bach T, Hall M, Gläß S, Schmucker M, et al. Digitale Radioonkologie. Der Onkologe. 2018:24(5):390-9. Epub 08.03.2018. doi: 10.1007/s00761-018-0340-0. 